

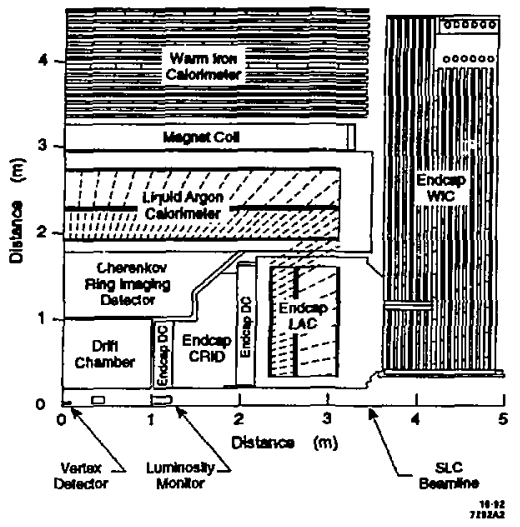

Figure 1: Cross-section of one quadrant of SLD showing the location of the endeap CRID.

tum particles can be identified. The momentum threshold for pions is $2.5 \mathrm{GeV} / \mathrm{c}$ and $\pi / \mathrm{K} / \mathrm{p}$ separation can be achieved for momenta up to about $30 \mathrm{GeV} / \mathrm{c}$.

\section{General Deschiption}

The endcap CRJD comprises two 2650 liter vessels located on either side of the SLC interaction point, with each vessel located between inner and outer endcap drift chambers as shown in Fig. 1. This detector system covers forward angular regions from $10^{\circ}$ to $35^{\circ}$, and from $145^{\circ}$ to $170^{\circ}$ with respect to the SLC beamline.

The vessels span the Z-axis (along the beamline) from 124 to $196 \mathrm{~cm}$, and extend from 20 to $146 \mathrm{~cm}$ in radius. Each vessel is organized into 10 azimuthal sectors and is equipped with a TPC in every other sector.

The basic elements of the endcap CRID are shown in Figs. 2 and 3. The TPCs consist of drift box and MWPC sections. The active area of a drift box is $43.2 \mathrm{~cm}$ wide and $28.0 \mathrm{~cm}$ along the drift field direction. Individual drift boxes are constructed with G10 backing and sides supporting a fused silica quartz window facing the mirrors. The drift box sensitive volume thickness is $5.15 \mathrm{~cm}$ at the high voltage end (radius $=54.6 \mathrm{~cm}$ ) and $5.60 \mathrm{~cm}$ at the $M W P C$ end (radius $=83.0 \mathrm{~cm}$ ), due to the $0.9^{\circ}$ taper of the $4 \mathrm{~mm}-\mathrm{m}$ hick quartz window. As a result of the taper, photo-electrons drift away from the quartz window, thus minimizing losses and possible distortion effects. Cherenkov radiation is focussed onto the drift boxes by an

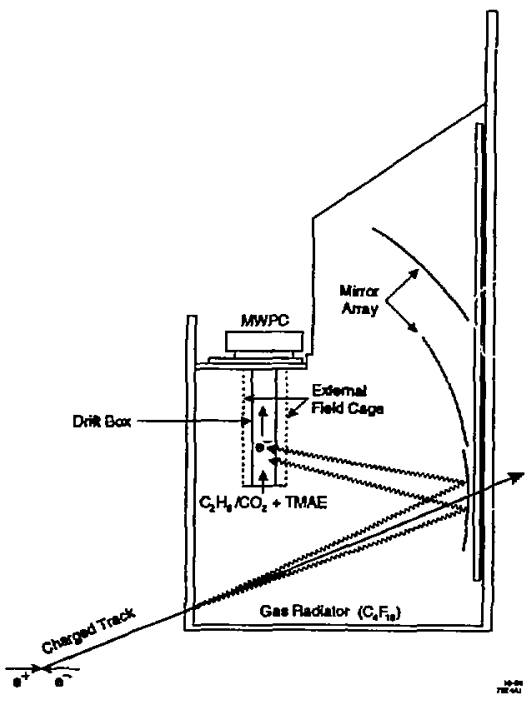

Figure 2: Endcap CRID crost-section quadrant displaying the main components.

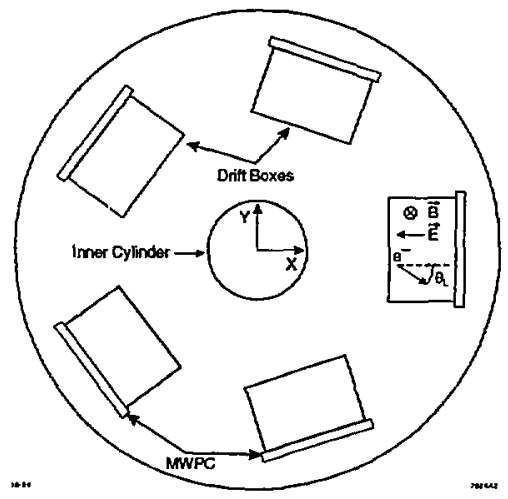

Figure 3: Endcap CRID view perpendicular to the beamline showing the placement of the Time Projection Chambers as well ay the magnetic (B) and electric (E) field direetions inside one TPC. Photo-electrons drift at an angle $\theta_{L}$ with respect to the electric field direction. 


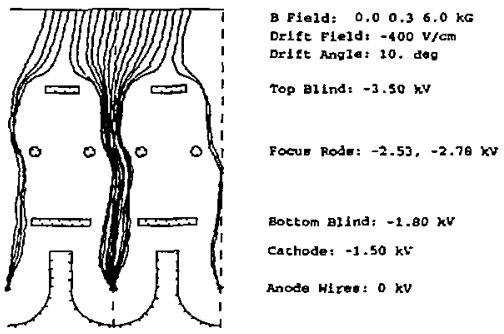

Figure 4: Focussing structure of the MultiWire Proportional Chambers. The simulated trajectories for electrons drifting with a $10^{\circ}$ Lorentz angle are also shown.

array of 60 spherical mirrors in each vessel. The mirtors are attached, in groups of six, to ladders mounted on the back plane of the vessels. For sectors without a TPC, the mirross are oriented in such a way as to focus light on one of the neighboring drift boxes.

The high voltage end of the drift box is kept at a potential of $-15 \mathrm{kV}$ which is degraded to ground via a resistor chain to provide a uniform $400 \mathrm{~V} / \mathrm{cm}$ electrir field. Field uniformity is guaranteed by a series of thin conducting strips precisely located on both sides of the quartz window and G10 surfaces, as well as by an external field cage (see Fig. 2). The electrostatics design closely follows that used in the bartel CRID [2].

Each MWPC contains 128 thin carbon wires ( $7 \mu \mathrm{m}$ diameter) enclosed in a focussing assembly with a wire spacing of $0.3505 \mathrm{~cm}$. The wire length is $6.8 \mathrm{~cm}$. The focussing structure (Fig. 4) includes two layers of etched copper sheets which provide focussing and serve as blinds to prevent UV avalanche photons from reaching the drift box volume where they would otherwise ionize TMAE. Pairs of transverse focus rods, located between the two blinds, provide a transverse electric field to correct the electron trajectories for the non-zero Lorentz angle; $\theta_{L} \simeq 10^{\circ}$ for the drift gas chosen. Cylindrical support rods made of GIO are placed between each layer of the focussing structure to prevent the blinds from buckling. This might occur due to the different coefficients of thermal expansion of the various materials. The diameter of the three support rods varies between $0.79 \mathrm{~mm}$ and $2.38 \mathrm{~mm}$. The larger rod produces a "shadow" in the center of the anode wires. The cathode is kept at $-1.5 \mathrm{kV}$, yiclding an average gain of $\sim 3 \times 10^{5}$ for single photo-electron avalanches, with TMAE present in the drift gas. The high resistivity $(R \simeq 29 \mathrm{k} \Omega)$ anode wires are read out on both ends to provide a measurement of the hit coordinate along the wire direction via charge division. The other two hit coordinates are reconstructed from the recorded drift time and the wire number

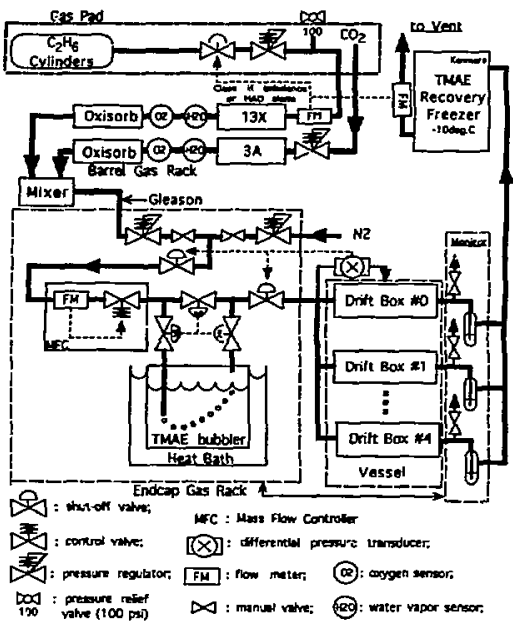

Figure 5: Drift gas delivery system.

of the hit.

Every TPC is equipped with 19 UV fiber fiducials whose positions on the quartz window are knowt. These fibers are used in various calibration and monitoring tasks: Lorentz angle and drift velocity measurements, study of electric field distortions and charge division resolution.

\section{FLUID SYSTEMS}

There are two main fluid systems: the drift gas and the radiator gas systems.

The essential features of the drift gas systcm are shown in Fig. 5. In order to decrease the electron drift vclocity, and thus reduce the magnitude of the Lorentz anglc, $\mathrm{CO}_{2}$ is added to the $\mathrm{C}_{2} \mathrm{H}_{6}{ }^{1}$-based drift gas to form a $\mathrm{C}_{2} \mathrm{H}_{6} / \mathrm{CO}_{2}$ $85 \% / 15 \%$ mixture. The resulting drift gas has good UV transparency in the useful range $\lambda \simeq 1600-2100 \AA$ and provides sufficient gain for single electron detection while maintaining proper quenching in the presence of TMAE. Other important properties of the gas mixture are its smal] diffusion coefficient to preserve good spatial resolution, and its long electron attenuation length to guarantee high detection efficiency.

The $\mathrm{C}_{2} \mathrm{II}_{6}$ and $\mathrm{CO}_{2}$ gas supplies are separately filtered through $13 \mathrm{X}$ and $3 \mathrm{~A}$ molecular sieves ${ }^{2}$ respectively, fol-

\footnotetext{
${ }^{1}$ UHP-grade $\mathrm{C}_{2} \mathrm{H}_{6}$ supplied by Air Liquide, LaPorle, $\mathrm{TX} 77572$, USA.

'Union Carbide Ca., Danbury, GT OGS17, USA.
} 

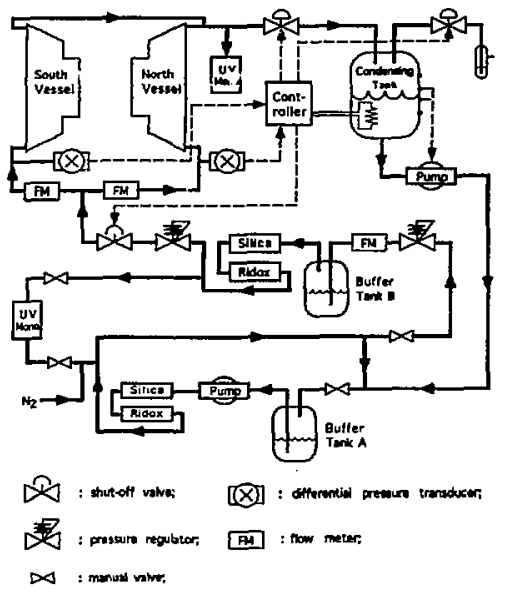

Figure 6: Radiator gas delivery and recirculation system.

lowed by Oxisorb $^{3}$ filters before being mixed. The mixture is then sent to two separate gas racks, one for each endcap, where a small amount of the photo-sensitive agent TMAE is added by bubbling through liquid TMAE maintained at $22^{\circ} \mathrm{C} .{ }^{4}$ At this temperature, the TMAE concentration is $0.05 \%$. TMAE ${ }^{5}$ undergoes an extensive purification procedure [3] before being used in the drift gas system.

The gas mixture flows through the drift boxes at the rate of $0.6 \mathrm{l} / \mathrm{min}$ per endcap which corresponds to a volume change in the drift boxes every hour. The drift box pressure relative to the vessel is typically 0.4 Torr. A dedjcated device is used to continuously monitor the average attenuation length of electrons in the drift gas mixture.

For gas radiator fluid, we opted for $\mathrm{C}_{4} \mathrm{~F}_{10}{ }^{6}$ rather than $\mathrm{C}_{5} \mathrm{~F}_{12}$ as used in the barrel CRJD. ${ }^{7}$ Some advantages of $\mathrm{C}_{4} \mathrm{~F}_{10}$ are its lower condensation point $\left(-2^{\circ} \mathrm{C}\right)$ and higher transparency in the range $\lambda \simeq 1600-1800 \AA$, where the quastum efficiency of TMAE is the highest. However, the index of refraction for $\mathrm{C}_{4} \mathrm{~F}_{10}(n=1.00153$ at $\lambda=1770 \AA)$ is slightly lower than for $\mathrm{C}_{5} \mathrm{~F}_{12}$, resulting in momentum thresholds $\sim 6 \%$ higher: $2.5 \mathrm{GeV} / \mathrm{c}$ for pions, $8.9 \mathrm{GeV} / \mathrm{c}$ for kaons, and $17.0 \mathrm{GeV} / \mathrm{c}$ for protons. The choice of $\mathrm{C}_{4} \mathrm{~F}_{10}$

\footnotetext{
3 MG Indurtries, Valley Forge, PA 19482, USA.

-It is planned to increase the terdperature of the TMAE bubbler to $26^{\circ} \mathrm{C}$.

SSupplied by RSA Co., Ardsley, NY 10502, USA.

- Perfluorobutane, Developmental Product L-11667, 3M Co., St. Paul, MN 55144, USA.

The bartel CPID currently usea $\& \mathrm{C}_{3} \mathrm{~F}_{12} / \mathrm{N}_{2}$ mixture as radistor gas to avoid the risk of conderustion.
}

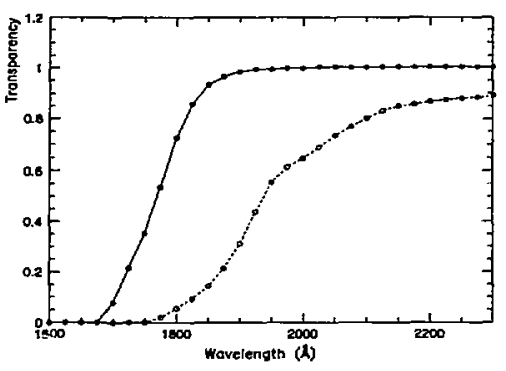

Figure 7: Transparency measurements in $1 \mathrm{~cm}$ of liquid C.F 10 kept inside a cell equipped with quartz windows, before (dashed line) and after purification (solid line).

as a gas radjator is appropriate due to its low chromatic dispersion in the relevant photon energy range $(\mathrm{d} n / \mathrm{d} E=$ $5.3 \times 10^{-6} \mathrm{eV}^{-1}$ in the range 6.5 to $7.5 \mathrm{eV}[4]$ ).

The radiator gas system (Fig. 6) is a closed loop system which maintains the vessel pressure constant by controlling the $\mathrm{C}_{\mathbf{4}} \mathrm{F}_{10}$ vapor pressure inside a condensing tank. Stable operation of the radiator gas system has been achieved for flows up to $2.5 \mathrm{l} / \mathrm{min}$ in each endcap, which corresponds to a volume change every 18 hours. The $\mathrm{C}_{4} \mathrm{~F}_{10}$ gas is recovered via a condensing tank inside a commercial freezer. The condensing tank effective temperature must be maintained constant to about $0.01^{\circ} \mathrm{C}$ to keep the $\mathrm{C}_{4} \mathrm{~F}_{10}$ pressure constant to 0.2 Torr. The $\mathrm{C}_{4} \mathrm{~F}_{10}$ effective temperature inside the tank is controlled by four Kapton foil heaters (total power $=300 \mathrm{~W}$ ) which are continuously immersed in the liquid. Input to the controller is provided by differential pressure transducers ${ }^{8}$ which measure the pressure inside cach endcap vessel with respect to atmospheric pressure.

Stability is maintained within \pm 0.02 Torr for llows up to $2.5 \mathrm{l} / \mathrm{min}$ in each endcap. A microprocessor is used to control the freezer compressor and the condensing tank bubbler based on the duty cycle of the heaters. This addition is necessary to achieve long term stability for flows greater than $1 \mathrm{l} / \mathrm{min}$ in each endcap. Some instabilities may occur due to the collection of nitrogen and ather gases that slowly leak into the system, do not condense in the tank, and accumulate until purged by the buhbler.

As the condensing tank fills up, liquid level indicators act as a trigger to pump out some of the liquid into Buffer Tank A. Liquid in that tank is contincously circulated through Silica $\mathrm{Gel}^{9}$ and Ridox ${ }^{10}$ filters for purification. As indicated in Fig. 7 , purification tests show dramatic improve-

\footnotetext{
Model 221A: MKS Instruments Inc., Andover, MA 01810, USA.

'Silica Gel Sorbeed WS: Costal Chemical, Pasadena, TX 77503, USA.

${ }^{10}$ Q5 Reactant: Engelhard Co., Elyris, OH 44035, USA.
} 


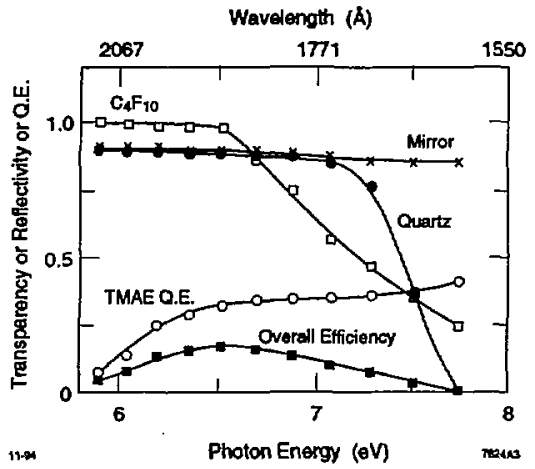

Figure 8: Endcap CRID estimated overall efficiency as a function of photon energy. Also shown are the different measured quantities entering the calculation: TMAE quantum efficiency, quartz window and $C_{4} F_{10}$ transparencies, and mirror refectivity.

ment in the UV transparency of liquid $C_{4} F_{10}$ after several passes through this filter combination. A small fraction of the liquid is transferred from the purification loop into Buffer Tank B for a final pass through a separate set of filterg before being sent to the vessels in the gas phase.

The $C_{4} F_{10}$ UV teansparency is measured with a monochromator at different stages of the recovery and filtering system (see Fig. 6). A sonar system inside the vessels monitors the gas composition at three different heights.

The overall performance of the endcap CRID can be characterized by the quantity $\mathrm{N}_{0}$, defined as $\alpha /(\hbar c) \int \epsilon \dot{\mathrm{c}} E$, where $c$ represents the overall efficiency for single photon detection as a function of photon energy $E$. We estimate $N_{0}$ to be approximately $70 \mathrm{~cm}^{-1}$ by laking the following measured quantities into account: TMAE quantum e/hciency [5], quartz window and $\mathrm{C}_{4} \mathrm{~F}_{10}$ radiator gas transparencies, and mirror reflectivity (see Fig. 8). This $\mathrm{N}_{0}$ estimate also includes a $68 \%$ efficiency for detection of single ploto-electrons corresponding to losses due to: fieldshaping strips and field cage wircs (14\%), photon conversion length (10\%), MWPC efficiency ( $10 \%)$, and electron attenuation in the drift box (2\%). As a result, the expected average number of ploto-clectrons per Clicrenkov ring is estimated to be $9-10$ for an average radiator thickness of $45 \mathrm{~cm}$. Improvements at the level of $\sim 10 \%$ may be possible by increasing the $\mathrm{C}_{4} \mathrm{~F}_{10}$ flow rate to improve UV transparency at shorter wavelength, and by increasing the amount of TMAE to reduce the photon conversion length. As can be seen in Fig. 8, the limiting factor at short wavelength comes from the quartz transparency rather than that of the radiator gas.

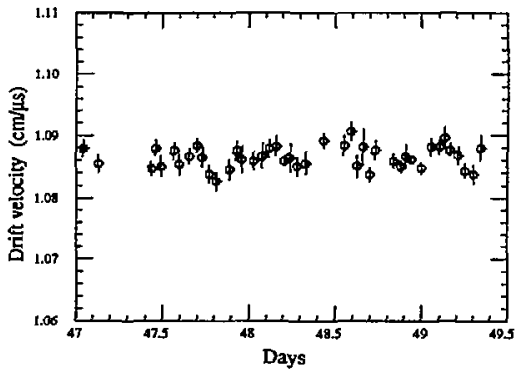

Figure 9: Drift velocity measurement as a function of time.

A dedicated MicroVAX computer is used for slow monitoring, time histories, and temperature control. The vessel temperature and the external plumbing temperatures are monitored and maintained at $\sim 30^{\circ} \mathrm{C}$. This elevated temperature is required to prevent TMAE from condensing. The water vapor and oxygen content of the drift and purge gases are monitored. Many other parameters are continuously monitored, including gas flow, drift box and vessel pressure, temperature sensors, heaters, radiator gas sonar velocity, drift gas composition, and cathode current.

\section{Experimental Performance}

Early data analysis results from the 1993 and 1994 SLD runs are presented below. Particle identification performance at the design level requires spatial resolution of $1 \mathrm{~mm}$ along the drift field and wire number directions, and $2 \mathrm{~mm}$ along the charge division direction. In order to achieve these resolutions, it is necessary to measure the Lorentz angle, the electron drift velocity, and the timing offset accurately each run (a typical run lasts $2-4$ hours).

The average conversion length during operation with $22^{\circ} \mathrm{C} \mathrm{TMAE}$ is measured to be $\mathrm{x.} . \mathrm{I} \pm 0.4 \mathrm{~cm}$, consistent with expectations (see for example $\operatorname{Ref}\{\{1\}$ ).

The electron drift velocity is measured on an hourly basis using hits from the UV fiber fiducials. Figure 9 shows a typical time dependence for measurements taken over a period of a few days. Velocities are determined to better than $\pm 0.5 \%$. The magnitude of the Lorentz angle is measured or a run by run basis with an average value $\left\langle\theta_{L}\right\rangle=9.65^{\circ}$ and root meen square (RMS) value of $0.24^{\circ}$, see Fig. 10 . The above measurements allow hit reconstruction with a spatial resolution at the $1 \mathrm{~mm}$ level or better along the drift field and wire number directions.

The UV fiber fiducials have also been used in a preliminary analysis of the charge division coordinate resolution. UV fibers shining across the wire plane are expected to 


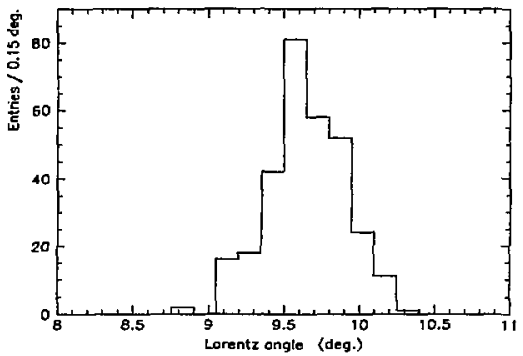

Figure 10: Distribution of the Lorentz angle measured on a run by run basis.

produce hits localized along that coordinate axis. By selecting hits within $2 \mathrm{~cm}$ of the quartz window and fitting the charge division coordinate distribution to a Gaussian for each wire, the preliminary average resolution is determined to be $2.3 \mathrm{~mm}$ with an RMS value of $0.7 \mathrm{~mm}$.

Another aspect of the above calibration process is that of timing oftsets. These are monitored by fitting the drift time distribution to determine the time corresponding to the physical end of the TPC. These fits require prior knowledge of the Lorentz angle, the drift velocity and the length of the TPC. The RMS value for the measured timing offset is determined to be $0.3 \mathrm{~mm}$. All of the above procedures have been automated and reside in the off-line analysis.

Finally, the data were examined for the existence of Cherenkov rings in both cosmic ray and colliding beam runs. An example of a ring is shown in Fig. Il along with a suggestive circle of $2.5 \mathrm{~cm}$ radius which corresponds to the radius expected for a $\beta \simeq 1$ particle. Figure 11 also shows that good spatial resolution has been achieved.

\section{Conclusions}

The endcap Cherenkov Ring Imaging Detector has been recently completed and is currently fully operational. Issues specific to the endeap regions have been dealt with successfully. In particular, the $10^{\circ}$ Lorentz angle required a special design for the MultiWire Proportional Chamber focussing structure. Initial performance indicates that the required $1 \mathrm{~mm}$ resolution in the hit reconstruction along the drift field direction and along the wire number direction can be achieved. First Cherenkov rings have been ohserved and work is underway to extract information from the tracking systems for ring-finding and alignment purposes.

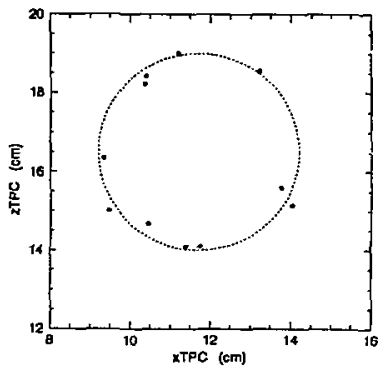

Figure 11: Example of a Cherenkov risg displayed in the TPC coordinate system. All hits are shown. The dashed circle of 2.5 cm radius is not the result of a fit but serves as a reference.

\section{REFERENCES}

[1] K. Abe et al, "Performance of the CRID at SLD," Nucl. Instr. and Meth., vol. A343, pp. 74-86, 1994, and references therein.

[2] K. Abe et al., "Electrostatic Design of the Barrel CRID and Associated Measurements," in Proc. of 5th Intn'l Conf. on Instrum. for Colliding Beam Physics, Novosibirsk, Russia, March 1990, pp. 221-237.

[3] K. Abe et at., "The Fluid Systems for the SLD Cherenkov Ring Imaging Detector," IEEE Trans. Nucl. Sci., vol. NS-40, pp. j93-597, 1993.

[4] G. Lenzen, E. Schyns, J. Thadome, and J. Werner, "The Use of Fluorocarbon Radiators in the DELPHI RICH Detectors," Nucl. Instr, and Meth. vol. A343, pp. 268-272, 1994.

[5] R.A. Holroyd, J.M. Press, C.L. Woody, and R.A. Johnson, "Measurement of the Absorption Length and Ahsolute Quantum Efficiency of TMAE and TEA froit Threshold to $120 \mathrm{~nm}$," Nucl. Iistc. and Meth., vol. A261, pp. 440-444, 1987. 


\section{DISCLAMMER}

This feport was prepared as an eccount of work spoesored by an agency of the United States Government. Neithet the United Steted Goverament nor any atency thereof, nor any of their employees, makes any wartanty. express or implied, or esumes any lezal liability or responsibility for the accuracy, completenesh, of useIulness of any information, apparatus, product, or process disclosed, or represents that its use would not infringe privately owned rights. Reference berein to any specific commercial product, process, or service by trade name, trademark manufac: turer, or otherwise does not necescarily constitute or imply its endorseneat, recommendation, or favoring by the United States Govemment or any agency thereof. The views and opinions of authos expressed herein do not necossurily state or reflest those of the United States Governmeat or any anency thereof. 